UDC: $519.6+336.7$

\title{
An Algorithm for Simulating the Banking Network System and Its Application for Analyzing Macroprudential Policy
}

\author{
M. F. Ansori ${ }^{1, a}$, N. Sumarti ${ }^{1, b}$, K. A. Sidarto ${ }^{1, c}$, I. Gunadi ${ }^{2, d}$ \\ ${ }^{1}$ Industrial and Financial Mathematics Research Group, Faculty of Mathematics and Natural Sciences, Institut \\ Teknologi Bandung, \\ Jl. Ganesa 10 Bandung, 40132, Indonesia \\ ${ }^{2}$ Bank of Indonesia Institute, \\ Jl. M.H. Thamrin 2 Jakarta, 10110, Indonesia
}

E-mail: ${ }^{a}$ mochfandiansori@s.itb.ac.id, ${ }^{b}$ novriana@math.itb.ac.id, ${ }^{\mathrm{c}}$ sidarto@math.itb.ac.id, ${ }^{\mathrm{d}}$ i_gunadi@bi.go.id

Received 26.09.2021.

Accepted for publication 18.10.2021.

\begin{abstract}
Modeling banking systems using a network approach has received growing attention in recent years. One of the notable models is that developed by Iori et al, who proposed a banking system model for analyzing systemic risks in interbank networks. The model is built based on the simple dynamics of several bank balance sheet variables such as deposit, equity, loan, liquid asset, and interbank lending (or borrowing) in the form of difference equations. Each bank faces random shocks in deposits and loans. The balance sheet is updated at the beginning or end of each period. In the model, banks are grouped into either potential lenders or borrowers. The potential borrowers are those that have lack of liquidity and the potential lenders are those which have excess liquids after dividend payment and channeling new investment. The borrowers and the lenders are connected through the interbank market. Those borrowers have some percentage of linkage to random potential lenders for borrowing funds to maintain their safety net of the liquidity. If the demand for borrowing funds can meet the supply of excess liquids, then the borrower bank survives. If not, they are deemed to be in default and will be removed from the banking system. However, in their paper, most part of the interbank borrowing-lending mechanism is described qualitatively rather than by detailed mathematical or computational analysis. Therefore, in this paper, we enhance the mathematical parts of borrowing-lending in the interbank market and present an algorithm for simulating the model. We also perform some simulations to analyze the effects of the model's parameters on banking stability using the number of surviving banks as the measure. We apply this technique to analyze the effects of a macroprudential policy called loan-to-deposit ratio based reserve requirement for banking stability.
\end{abstract}

Keywords: banking stability, interbank network, difference equation, simulation, macroprudential policy

Citation: Computer Research and Modeling, 2021, vol. 13, no. 6, pp. 1275-1289.

This work was supported by the Indonesian Directorate General for Higher Education's PMDSU Batch III scholarship.

(C) 2021 Moch. Fandi Ansori, Novriana Sumarti, Kuntjoro Adji Sidarto, Iman Gunadi This work is licensed under the Creative Commons Attribution-NoDerivs 3.0 Unported License. To view a copy of this license, visit http://creativecommons.org/licenses/by-nd/3.0/ or send a letter to Creative Commons, PO Box 1866, Mountain View, CA 94042, USA. 


\section{Introduction}

A banking system is a collection of interconnected banks, through direct or indirect relationships. Directly connected banks interact in the interbank market, one borrows funds, and the other lends. Meanwhile, indirect connection means that banks could share the same risk given that they invest in similar types of assets. Our paper focuses on the direct connection. Borrowing banks borrow funds to meet their liquidity needs such as obligations to meet withdrawals or interest payments on customer deposits and to return loans to other banks if any. Lending banks lend funds to other banks that have the potential to provide profits rather than letting the money be excess liquids. On the one hand, the interaction of banks in the interbank market can provide a safety net for certain banks, on the other hand, if there is a bank that fails to maintain its liquidity position and had loans from other banks in the previous period, then the liquidity shock will have the potential to disturb the lender bank's liquidity. The latter is the source of systemic risk (i. e., a crisis that occurs in one bank can spread to other banks), which is studied by Iori et al. in [Iori, Jafarey, Padilla, 2006]. In an indirect connection case, the source of systemic risk is a strong enough failure of one bank which can cause the fall of its assets' price, and this can lead to a crisis in the neighborhood which holds a similar type of assets [Allen, Gale, 2000].

Iori et al. in [Iori, Jafarey, Padilla, 2006] proposed a model to study the banking system for analyzing systemic risks in the interbank network. The model has the form of difference equations consisting of several balance sheet variables such as deposit, equity, loan, liquid asset, and interbank lending (or borrowing). Every bank faces shocks in deposits and loans. Their balance sheet is updated at the beginning or end of each period. In the model, banks are grouped into either potential lenders or borrowers. The potential borrowers are those that have lack of liquidity and the potential lenders are those which have excess liquids after dividend payment and channeling new investment. Those borrowers have some percentage of linkage to random potential lenders for borrowing funds to maintain their safety net of the liquidity. If the demand of borrowing funds can meet the supply of excess liquids, then the borrower bank survives. If not, they are deemed to be in default and will be removed from the banking system.

Some related works on the banking system modeling vary based on the modeling approach they use. The papers [Eisenberg, Noe, 2001; Rogers, Veraart, 2013; Elsinger, 2009; Visentin, Battiston, D'Errico, 2016] study the debt contracts in interbank networks using a clearing procedure to determine the optimal strategy of each bank simultaneously. Several papers [Nier et al., 2008; Gai, Kapadia, 2010; Battiston et al., 2012; Eboli, 2010; May, Arinaminpathy, 2010] depict the banking system as a weighted and directed graph where the spread of systemic risk through interbank lending is viewed as Erdös - Renyi random networks. In some notable works [Brummitt, Kobayashi, 2015; Bargigli et al., 2015; Poledna et al., 2015], a banking system is assumed to be a multilayer network where each layer has different structure such as seniority of risk assets, long and short-term assets trading, and foreign exchange exposure. For more discussions of the banking network models, see some reviews in [Hüser, 2015; Caccioli, Barucca, Kobayashi, 2018].

The study in which the above-mentioned model was presented by Iori et al. has been followed by a rapidly increasing body of research recently. The model was developed further by some researchers by adding various aspects in economics and banking to examine their impacts on systemic risks in the interbank market. The role of the central bank in the model in enhancing the stability of the banking system is studied by [Georg, Poschmann, 2010]. Ref. [Jiang, Fan, 2019] explores the effects of overlapping portfolios of assets held by banks. The existence of shadow banks in the banking system is investigated by [Fan, Pan, 2020]. The authors of [Gao, Fan, 2020] examine the consequences of macroeconomic fluctuations in the return of assets.

There are two main reasons why we use the model of Iori et al. for modeling the banking system. First, the model covers the time series dimension of liquidity risks. In each period, shocks in deposits 
and investments cause liquid assets shocks and at some point can result in the bank suffering the lack of liquidity. Second, it covers the cross-section dimension of liquidity risks. The failure of one bank because of the lack of liquidity can hit the liqudity of other banks which have lent their funds to the failed bank through an interbank market.

Although the model gives such richness, the interbank borrowing-lending mechanism in the model is explained for the most part in a qualitative manner rather than by using a detailed mathematical or computational analysis. This motivates us to intensify the mathematical parts of interbank borrowinglending and to provide a full computational algorithm to simulate the model. It will be useful for noneconomists and bankers such as mathematicians and computer scientists to understand how the interbank market works in the banking system. In this paper, we also perform some simulations to see the effects of the model's parameters on banking stability using a number of surviving banks as a measure. Our results can be a tool for analyzing other aspects that emerge in the banking system.

Time series and cross-sectional dimensions are two main dimensions used by banking regulators in formulating macroprudential policies. Macroprudential policy is a policy that aims to maintain the stability of the financial system as a whole by mitigating systemic risks. Since the model of Iori et al. accommodates the time series and cross-section dimensions, this model is very suitable for analyzing macroprudential policy instruments. In this paper, we apply the model to analyze a macroprudential instrument in Indonesia called the loan-to-deposit ratio based reserve requirement (LDR-RR). LDR-RR is a minimum reserve that must be maintained by a bank in the Bank of Indonesia (the central bank of Indonesia) in a percentage of the third part fund which is calculated based on the difference between the bank's LDR and the target LDR set by the Bank of Indonesia. The purpose of this instrument is to strengthen the banking intermediation function without neglecting the control of liquidity risks. In its implementation since 2011, the LDR-RR instrument has undergone several changes in parameter values as an effort to control the growth of the banking credit [Wijayanti, Adhi, Harun, 2020]. In the dynamics of the bank's balance sheet, controlling the credit will have an impact on the level of liquidity. Meanwhile, liquidity is the main subject of the model of Iori et al. Therefore, we are motivated to use the model to analyze the impact of changes in the LDR-RR's parameter values on the banking stability. Our result can be beneficial for the regulator of the LDR-RR instrument, which is the Bank of Indonesia, because it can be used as an alternative consideration in planning changes to the regulation of LDR-RR in the future.

\section{Model}

First, we review the banking system model of Iori et al. Suppose a banking system consists of $N$ banks and each bank is assigned an index number $k, k=1,2, \ldots, N$, and operates in discrete time $t=$ $=0,1,2, \ldots, T$. At time $t-1$, every bank $k$ has a balance sheet composition consisting of: deposits $D_{k, t-1}$, equity $E_{k, t-1}$, loans $L_{k, t-1}$, liquid assets $A_{k, t-1}$, and interbank lending (or borrowing) $M_{k, t-1}$. Liquid assets consist of reserve requirements in the central bank $R_{k, t-1}$ and excess liquids $A_{k, t-1}-$ $-R_{k, t-1}$. Loans are the sum of investments $L_{k, t-1}=\sum_{s=1}^{\tau} I_{k, t-s}$ where $I_{k, t-s}$ is investment and $\tau$ is the investments' maturity time. The model assumes that the creditor only pays interest of loan when it is not due, and there is no nonperforming loan factor. When the bank has interbank lending (borrowing), we write $M_{k, t-1}<0\left(M_{k, t-1}>0\right)$. The model assumes that the interbank borrowing is a one-period loan that requires full payment in the next period.

At the end of period $t-1$, or we can say at the beginning of period $t$, the liquidity of each bank $k$ yields

$$
A_{k, t-1}=D_{k, t-1}+E_{k, t-1}-L_{k, t-1}+M_{k, t-1} \text {. }
$$

At time $t=0$, the variables $D_{k,-1}$ and $E_{k,-1}, L_{k,-1}$ are determined exogenously, which means that their value is independently determined and does not depend on the value of other variables, and there is no 
interaction between banks in the interbank market, so $M_{k,-1}=0$. For time $t>0$, the update of each variables is described below.

Deposits are assumed to follow a simple model involving the average amount of deposits $\bar{D}>0$ and a random shock $\varepsilon_{D, t} \sim \mathrm{N}(0,1)$ :

$$
D_{k, t}=\left|\bar{D}+\bar{D} \sigma_{D} \varepsilon_{D, t}\right|
$$

where $\sigma_{D}>0$ is the volatility of deposits. Deposits could increase (or decrease) due to the resultant of the customer's savings and withdrawals. Here $\mathrm{N}(0,1)$ denotes the standard normal distribution.

The bank gets interest payments from all investments owned and receives return of matured investment, and there is a change in deposits and the bank must pay interest on deposits, then at this moment the bank's liquid assets become:

$$
A_{k, t}=A_{k, t-1}+r_{L} \sum_{s=1}^{\tau-1} I_{k, t-s}+\left(1+r_{L}\right) I_{k, t-\tau}+\left(D_{k, t}-D_{k, t-1}\right)-r_{D} D_{k, t-1},
$$

where $r_{L}$ is the loan interest rate and $r_{D}$ is the deposit interest rate.

If the bank has previous interbank borrowing, then at this stage the bank must repay it either all in cash or nothing. Therefore, banks will make payments only when their liquid assets are greater than their interbank borrowing plus interest (i. e., $\left.\left(1+r_{M}\right) M_{k, t-1}\right)$, where $r_{M}$ is the interbank interest rate. The liquid assets will be updated accordingly.

At this stage, depending on liquid assets, there will be two groups of banks: potential lender banks, which have positive liquid assets, and potential borrower banks, which have negative liquid assets. The borrower banks issue a demand for loans equal to $\left(1+r_{M}\right) M_{k, t-1}-A_{k, t}$. The interbank borrowing is made only for short-term liquidity needs and is not made for investments.

The potential lender banks are assumed to pay dividends first and then make investment as their priority before their excess liquidity is made available to borrower banks in the interbank market.

Dividends are paid if the bank meets its target equity: the deposits ratio $E_{k, t} / D_{k, t}>\chi$, where $0<$ $<\chi<1$ and $E_{k, t}=A_{k, t}+\sum_{s=1}^{\tau-1} I_{k, t-s}-D_{k, t}$. The amount of dividend $d_{k, t}$ is calculated as follows:

$$
d_{k, t}=\max \left\{0, \min \left\{r_{L} L_{k, t-1}-r_{D} D_{k, t-1}, A_{k, t}-R_{k, t}, A_{k, t}+\sum_{s=1}^{\tau-1} I_{k, t-s}-(1+\chi) D_{k, t}\right\}\right\},
$$

where $R_{k, t}=\rho D_{k, t}$ for some reserve requirement portion $0<\rho<1$. The amount of dividend is restricted to the equal net profit, but only if it violates either the minimum reserve or the target ratio. If the target ratio is not fulfilled, then the bank does not pay any dividend.

After dividend payment, the bank's liquid assets are updated $A_{k, t}:=A_{k, t}-d_{k, t}$, and then the bank makes a new investment $I_{k, t}$ which is calculated as

$$
I_{k, t}=\min \left\{\left|\mu+\mu \sigma_{\mu} \varepsilon_{\mu, t}\right|, \max \left\{0, A_{k, t}-R_{k, t}\right\}\right\},
$$

where $\mu>0$ is the average investment opportunity with volatility $\sigma_{\mu}$ and shock $\varepsilon_{\mu, t} \sim \mathrm{N}(0,1)$. $\max \left\{0, A_{k, t}-R_{k, t}\right\}$ is the maximum amount that the bank can invest. After this investment, the asset liquids are updated again: $A_{k, t}:=A_{k, t}-I_{k, t}$.

At this point, the interbank borrowing and lending will take place. The borrower banks make a random order contact to the lender banks with percentage linkage $c$. The amount of funds that one bank borrows from others is the minimum of demand and supply. If they have reached an agreement of demand and supply funds, then funds are transferred and the liquid assets of each bank are updated. 
For the sake of simplicity, if the lender banks' supply cannot reach the borrower bank's demand in full, then the interbank lending will not be made. Therefore, the bank which failed to borrow is deemed to be in default and is removed from the banking system. Other banks that survive at this period update their equity

$$
E_{k, t}:=A_{k, t}+L_{k, t}-D_{k, t}-M_{k, t}
$$

\section{Interbank Borrowing-Lending}

The interbank borrowing-lending has a significant role in the economic cycle of the banking system. We explain its mechanism in the model of Iori et al. using mathematical notations. Let $\Omega_{t}^{\mathrm{PL}}$, $\Omega_{t}^{\mathrm{B}}, \Omega_{k, t}^{\mathrm{MB}}$, and $\Omega_{t}^{\mathrm{S}}$ be the set of potential lenders, the set of borrowers, the set of banks that give loans to the bank $k$, and the set of surviving banks at time $t$, respectively.

First we explain the moment when the banks are classified into two groups and the banks who have debts make repayment to the previous lenders.

1. If (i) bank $k$ has excess liquidity and lent funds in the previous period $\left(A_{k, t}>0 \& M_{k, t-1} \leqslant 0\right)$ or (ii) bank $k$ has sufficient funds to pay the previous period's debts to other banks $\left(A_{k, t}>0 \&\right.$ $\left.M_{k, t-1}>0 \& A_{k, t} \geqslant\left(1+r_{M}\right) M_{k, t-1}\right)$ [Jiang, Fan, 2019], then bank $k$ is placed in $\Omega_{t}^{\mathrm{PL}}$. Especially for condition (ii), bank $k$ must first pay the debts:

(a) Each bank $j \in \Omega_{k, t-1}^{\mathrm{MB}}$ gets repayments, hence its liquid assets are updated to: $A_{j, t}:=A_{j, t}+$ $+\left(1+r_{M}\right) M_{k, j, t-1}$. At the same time, its interbank assets are updated to: $M_{j, t-1}:=M_{j, t-1}+$ $+M_{k, j, t-1}$

(b) After paying the debts, the liquid assets of bank $k$ are updated to: $A_{k, t}:=A_{k, t}-\left(1+r_{M}\right) M_{k, t-1}$. At the same time its interbank liabilities become zero, $M_{k, t-1}:=0$.

2. Other than conditions (i) and (ii), bank $k$ is included in $\Omega_{t}^{\mathrm{B}}$. The amount of the liquidity needs of bank $k$ is $G_{k, t}$ with $G_{k, t}=\left(1+r_{M}\right) M_{k, t-1}-A_{k, t}$.

The next is the interbank borrowing-lending process. For all banks $k \in \Omega_{t}^{\mathrm{B}}$, bank $k$ has links to some random banks from $\Omega_{t}^{\mathrm{PL}}$. The percentage of linkage is $c$. Thus, $\Omega_{k, t}^{\mathrm{MB}}$ is a random permutation of $\Omega_{t}^{\mathrm{PL}}$, where $\# \Omega_{k, t}^{\mathrm{MB}}=c \# \Omega_{t}^{\mathrm{PL}}$. The notation \# denotes the set cardinality. If the total funds that can be lent by banks in $\Omega_{k, t}^{\mathrm{MB}}$ are sufficient for the liquidity needs of bank $k$, then the process of borrowing funds is carried out. The sufficient condition is

$$
\sum_{j \in \Omega_{k, t}^{\mathrm{MB}}} \max \left\{A_{j, t}-R_{j, t}, 0\right\} \geqslant G_{k, t}
$$

If the sufficient condition (7) is fulfilled, then the interbank lending is made. The process is described as follows. Write $\Omega_{k, t}^{\mathrm{MB}}$ as $\Omega_{k, t}^{\mathrm{MB}}=\left\{j_{1}, j_{2}, \ldots, j_{v}\right\}$, where $v=\# \Omega_{k, t}^{\mathrm{MB}}$. Suppose the lending funds from bank $j_{i} \in \Omega_{k, t}^{\mathrm{MB}}$ to bank $k$ are carried out sequentially, first for index $j_{1}$, then $j_{2}$, and so on until $j_{v}$. Suppose $B_{k, t}$ are the funds that the bank $k$ still needs to borrow to meet its liquidity needs $G_{k, t}$. It is clear that at the initial moment $B_{k, t}=G_{k, t}$. For $i=1$ to $i=v$ do:

$$
\begin{aligned}
M_{k, j_{i}, t} & =\min \left\{B_{k, t}, \max \left\{A_{j_{i}, t}-R_{j_{i}, t}, 0\right\}\right\}, \\
A_{j_{i}, t} & :=A_{j_{i}, t}-M_{k, j_{i}, t}, \\
M_{j_{i}, t} & :=M_{j_{i}, t}-M_{k, j_{i}, t}, \\
B_{k, t} & :=B_{k, t}-M_{k, j_{i}, t} .
\end{aligned}
$$


If bank $k$ meets the criteria of (7) and has debts to other banks at time $t-1$, then bank $j$ in $\Omega_{k, t-1}^{\mathrm{MB}}$ gets the debt payment. So the liquid assets of bank $j \in \Omega_{k, t-1}^{\mathrm{MB}}$ are updated to $A_{j, t}:=A_{j, t}+\left(1+r_{M}\right) M_{k, j, t-1}$, and at the same time $M_{j, t-1}:=M_{j, t-1}+M_{k, j, t-1}$. After paying the debts, the liquid assets of bank $k$ are updated to $A_{k, t}:=0$, and at the same time bank $k$ has no debt to banks in $\Omega_{k, t-1}^{\mathrm{MB}}$, i. e., $M_{k, t-1}:=0$. However, now bank $k$ has debts to banks in $\Omega_{k, t}^{\mathrm{MB}}$ which are $M_{k, t}=G_{k, t}$.

\section{Algorithm}

The measure of the stability of the banking system in this model is the number of banks that survive at each time $t$, which is denoted as $S_{t}=\# \Omega_{t}^{\mathrm{S}}$. $S_{t}$ acts as the output of the model's simulation algorithm below.

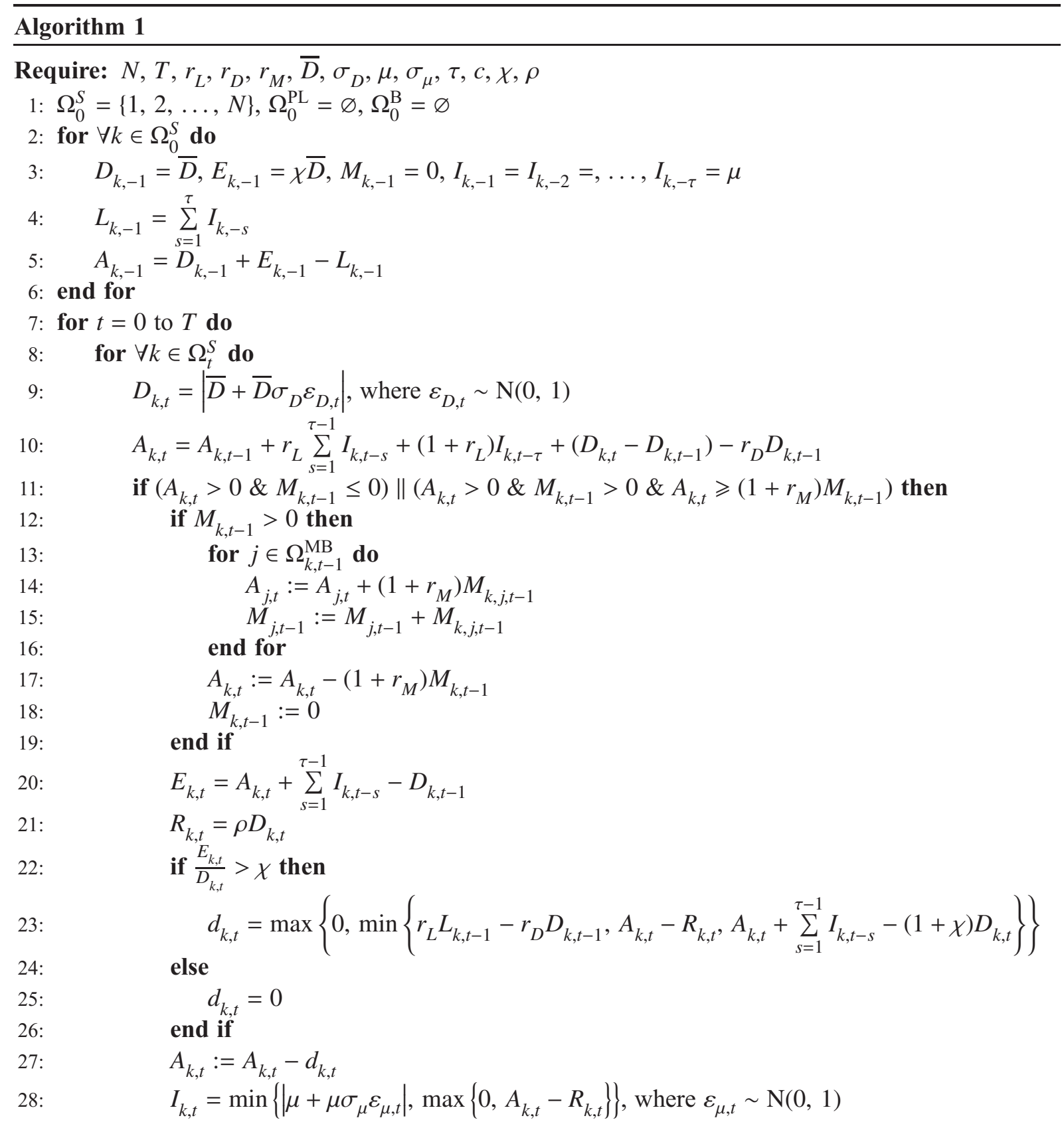




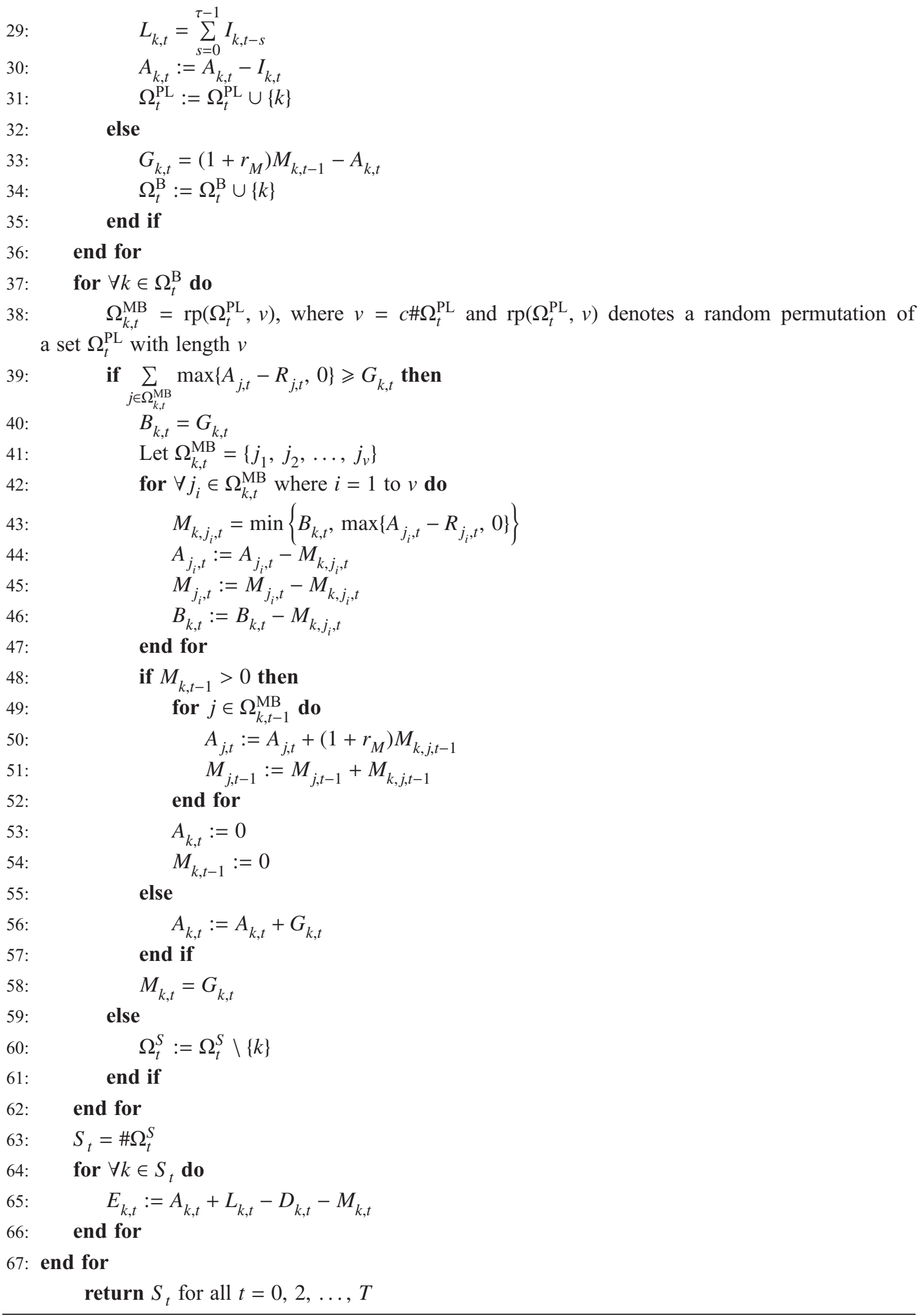




\section{Simulation}

Based on Algorithm 1, some simulations are performed to see the effects of the model's parameters on the stability of the banking system using the values given in Table 1. Most of those values are taken from [Iori, Jafarey, Padilla, 2006] and the rest is adjusted for giving a better picture.

Table 1. Description and value of the model's parameters

\begin{tabular}{clc}
\hline Parameter & \multicolumn{1}{c}{ Description } & Value \\
\hline$N$ & The number of banks & 400 \\
$T$ & Simulation end time & 100 \\
$r_{D}$ & Deposit interest rate & $0,1 \%$ \\
$r_{L}$ & Loan interest rate & $1 \%$ \\
$r_{M}$ & Interbank interest rate & $0,5 \%$ \\
$D$ & Deposit average & 1000 \\
$\sigma_{D}$ & Deposit volatility & 0,5 \\
$\mu$ & Investment opportunity average & 400 \\
$\sigma_{\mu}$ & Investment opportunity volatility & 0,5 \\
$\tau$ & Investment maturity time & 3 \\
$c$ & Interbank linkage percentage & $1 \%$ \\
$\chi$ & Target equity:deposit ratio & $30 \%$ \\
$\rho$ & Reserve requirement portion & $12 \%$ \\
\hline
\end{tabular}

The effect of the deposit average on the stability of the banking system is shown in Figure 1, $a$. It can be seen that, the higher the deposit average, the more stable the banking system. Since there is no increase in the average demand for loans, the excess funds resulting from increment in the deposit average will increase the liquid assets. Therefore, the potential for liquidity shortages will decrease. This decreases the need of the banks for loan funds in the interbank market, thus the banks' failures can be avoided.

Meanwhile, the case of deposit volatility is the opposite. Figure $1, b$ shows that, the greater the deposit volatility, the less stable the banking system. The deposit volatility can result in two things: an increase in deposits, which means that more people save their funds, or a decrease in deposits, which means that more people withdraw their funds. When deposits increase, liquid assets increase, and vice versa. As a result, when the deposit volatility is high, the potential for insufficient liquid assets to meet liquidity needs to be increased. Thus, the banks will be more likely to borrow funds from the interbank market. When the supply of funds in the interbank market does not meet their needs, the banks will fail.

Figure 1, $c$ and 1, $d$ show that, on both investment opportunity average and volatility, an increment in their value causes the banking system to become less stable. The increasing demand for loans will increase the distribution of new loans, so that the liquid assets of the bank in $\Omega_{t}^{\mathrm{PL}}$ will decrease. This will reduce the supply of loanable funds in the interbank market. As a consequence, the loan needs for banks that lack liquidity will not be met, and the bank will fail. The effects of high volatility in investment opportunity on the banking system can be explained in a similar way.

Because loan repayments are only made when the time is due and with full repayments, a shorter maturity period will allow the banks to have sufficient liquidity, so there are rarely banks that will lack liquidity. As a result, the potential for bank failure is low, and the banking system becomes more stable. See Figure 2, $a$.

The impact of interbank linkage on the stability of the banking system is very clear. When the linkage percentage is higher, there will be more potential lender banks from which funds can be borrowed. So, the liquidity needs will be more easily met, the number of failed banks will be less, and the banking system will become more stable. See Figure 2, $b$. 


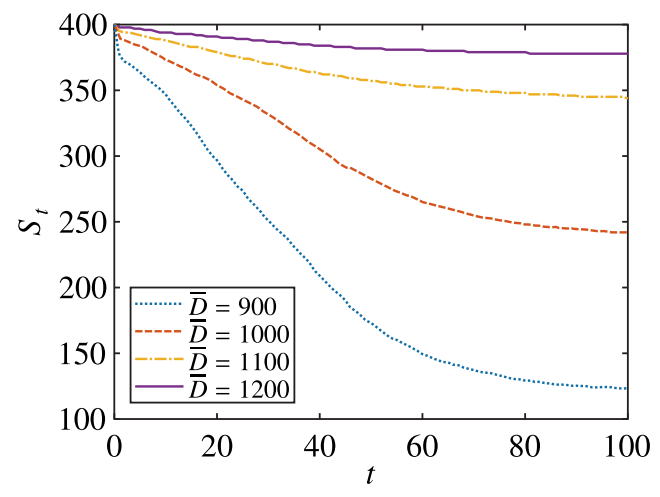

(a)

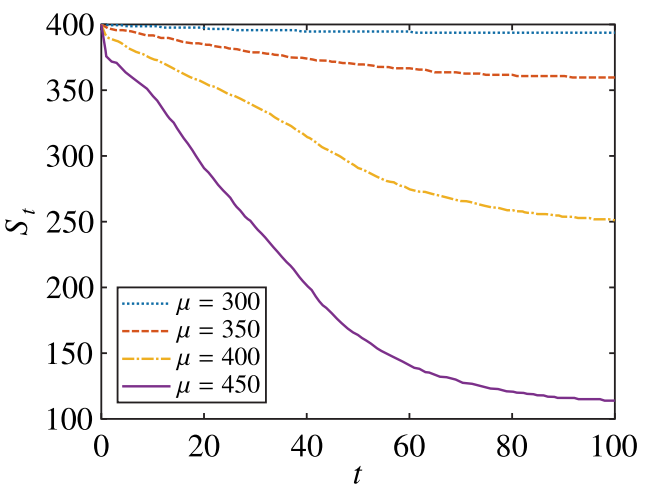

(c)

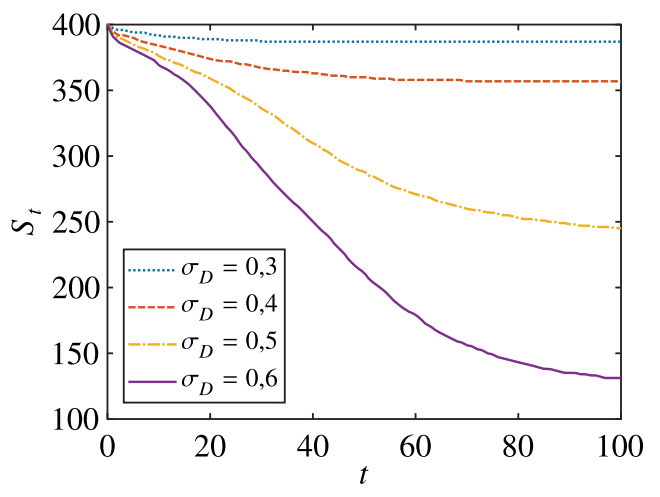

(b)

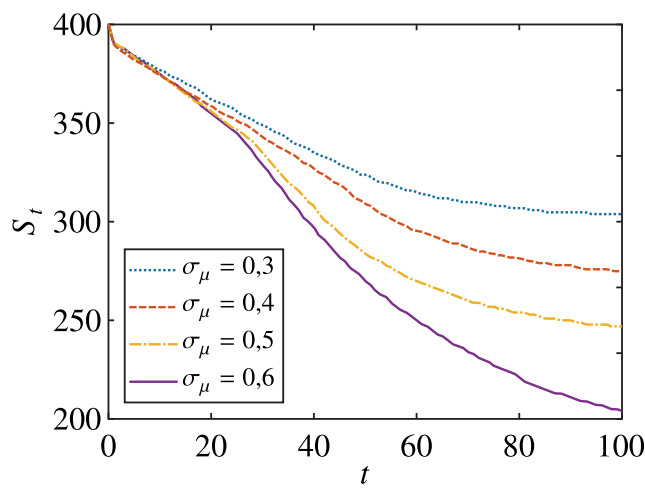

(d)

Figure 1. The number of surviving banks $S_{t}$ at each time $t$ for different values of parameters. Panels (a), (b), (c), and (d) show the deposit average $\bar{D}$, the deposit volatility $\sigma_{D}$, the average investment opportunity $\mu$, and the investment opportunity volatility $\sigma_{\mu}$, respectively. The higher $S_{t}$, the more stable the banking system

The target equity: the deposit ratio in the criteria of dividend payments can also affect the stability of the banking system, as shown in Figure 2, c. The higher the target ratio, the more difficult it is to achieve the criteria for dividend payment. So, the liquid assets are not reduced much due to the lack of dividend payments. The banks in the $\Omega_{t}^{\mathrm{PL}}$ set will have larger supply of funds to lend in the interbank market.

Unlike the previous parameters, using the same measure for the stability of the banking system, i. e., $S_{t}$, the impact of $\rho$ on the value of $S_{t}$ cannot be clearly determined, as shown in Figure $2, d$. Therefore, the analysis is carried out in a different way, namely, using the number of banks that survive at the end of simulation, which is $S_{T}$ as the new measure of the stability of the banking system, see Figure 3. In this way, as the value of $\rho$ moves from 0 to 0,3 with increment 0,005 , it can be seen that the stability of the banking system moves up and down (marked by black dots), but still has a tendency to form a parabolic curve as shown by the red curve. This red curve is obtained by using polynomial fitting polyfit in Matlab software. The curve is $S_{T}$ as a function of $\rho$, which is given by the following equation:

$$
S_{T}(\rho)=-1385,56 \rho^{2}+518,74 \rho+219,37,
$$

where the maximum value of $S_{T}(\rho)$ coincides with $\rho=18,72 \%$. 


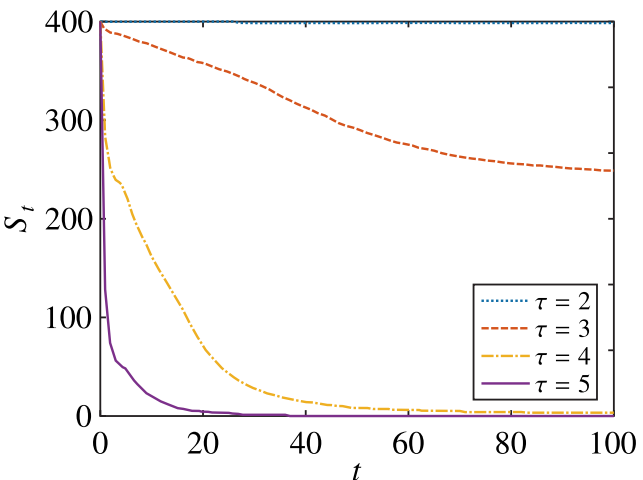

(a)

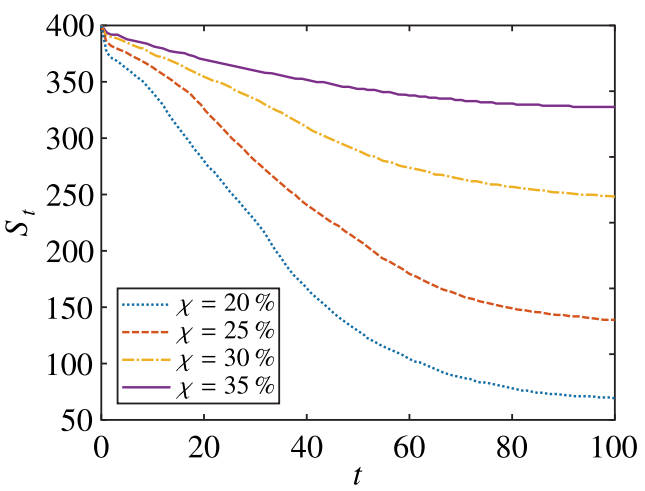

(c)

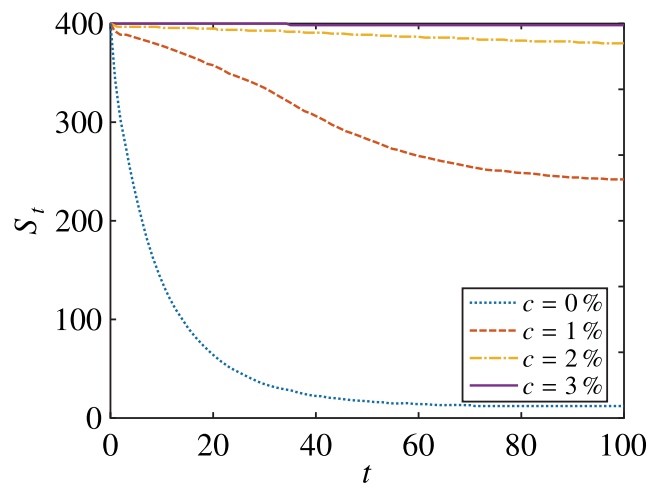

(b)

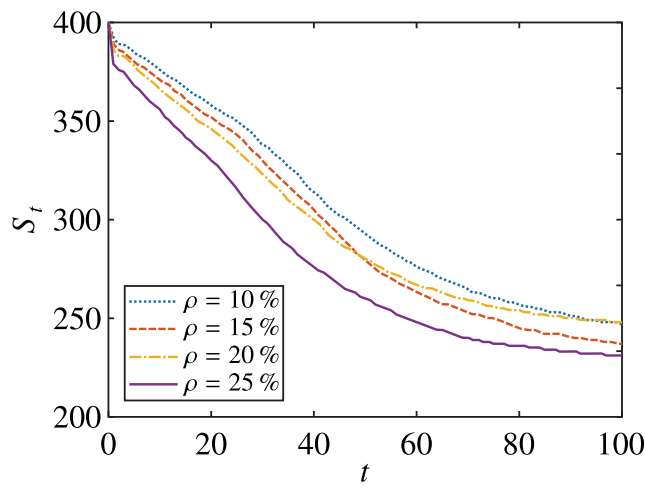

(d)

Figure 2. The number of surviving banks $S_{t}$ at each time $t$ for different values of parameters. Panels (a), (b), (c), and (d) show the investment maturity time $\tau$, interbank linkage percentage $c$, target equity: the deposit ratio $\chi$, and the reserve requirement portion $\rho$, respectively. The higher $S_{t}$, the more stable the banking system

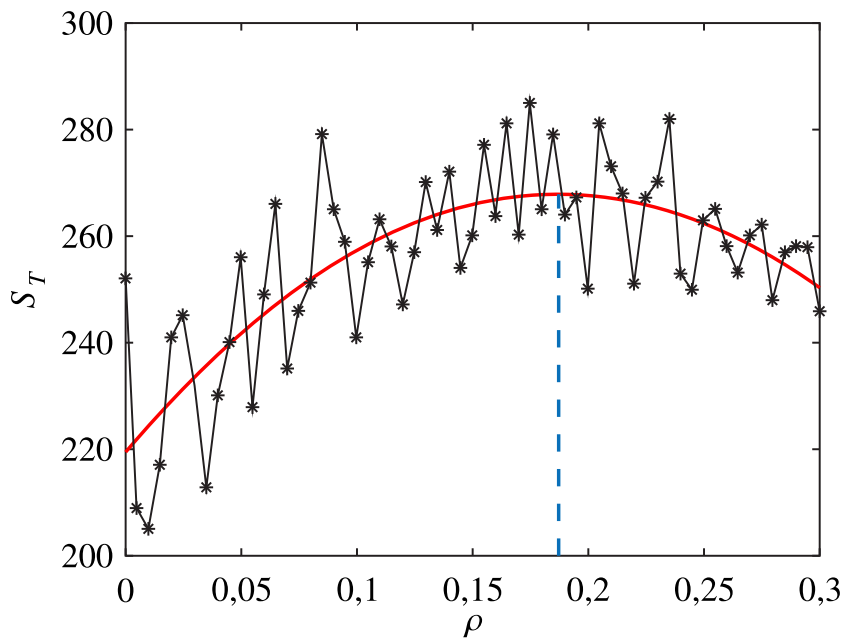

Figure 3. Relation between the number of surviving banks at the end of simulation $S_{T}$ with reserve requirement portion $\rho$. The black dots represent values of $S_{T}$ with respect to $\rho$ that are obtained from the model simulation. The red line is a quadratic curve that gives the best fit of $\left(\rho, S_{T}\right)$ points

\section{LDR-RR Instrument}

The LDR-RR instrument is included in the reserve requirement (RR) components. RR is the minimum amount of funds that must be maintained by banks, the amount of which is determined by 
the Bank of Indonesia at a certain percentage of the third party fund (TPF). In Indonesia, RR is the sum of three types of RR: primary RR, secondary RR, and LDR-RR. The primary RR is a monetary policy to control money supply. The secondary RR is a policy to maintain banking liquidity. The LDR-RR is the Bank of Indonesia's macroprudential policy that aims to strengthen the banking intermediation function without neglecting liquidity risks.

In [Bank of Indonesia Regulation, 2010], the description of the LDR-RR calculation is explained as follows. There are five parameters in the LDR-RR instrument: 1) the lower limit of LDR target, 2) the upper limit of LDR target, 3) the lower disincentive parameter, 4) the upper disincentive parameter, and 5) the incentive capital adequacy ratio (CAR). The LDR-RR calculation is carried out as follows:

1. In the event that the bank's LDR is within the target LDR range (i. e., between the lower limit and the upper limit of the target), the LDR-RR of the bank is $0 \%$ (zero percent) of TPF in rupiah.

2. In the event that the bank's LDR is smaller than the lower limit of LDR target, the bank's LDR-RR of the bank is the result of multiplication between the lower disincentive parameter, the difference between the lower limit of LDR target and the bank's LDR, and TPF in rupiah.

3. In the event that the bank's LDR is greater than the upper limit of LDR target and the bank's CAR is smaller than the incentive CAR, the bank's LDR-RR is the result of multiplication between the upper disincentive parameter, the difference between the bank's LDR and the upper limit of LDR target, and TPF in rupiah.

4. In the event that the bank's LDR is greater than the upper limit of LDR target and the bank's CAR is equal to or greater than the incentive CAR, then the bank's LDR-RR is $0 \%$ (zero percent) of TPF in rupiah.

Here TPF is deposits, and CAR is assumed to be the ratio of equity and loans. Based on the explanation above, the calculation of LDR-RR in mathematical notation can be written as:

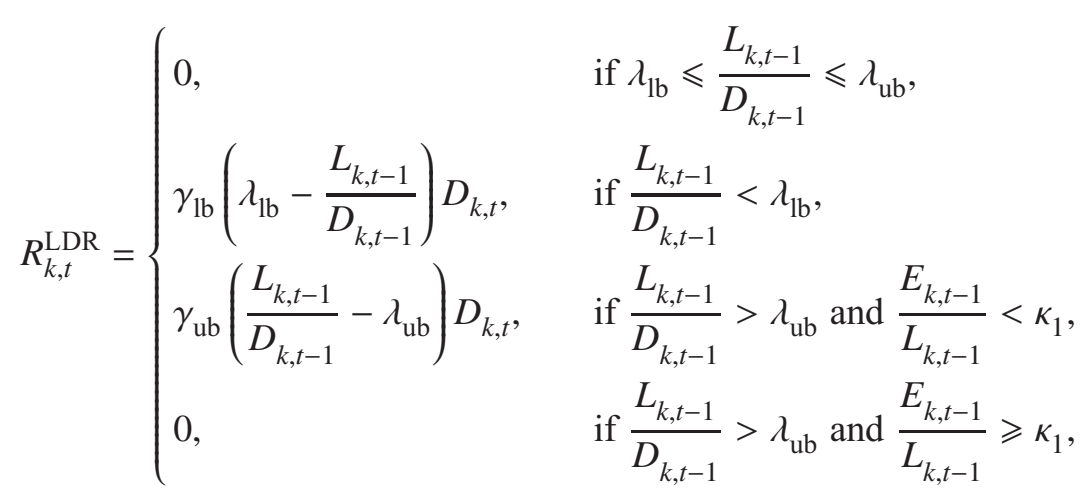

where $\lambda_{\mathrm{lb}}$ represents the lower limit of LDR target, $\lambda_{\mathrm{ub}}$ represents the upper limit of LDR target, $\gamma_{\mathrm{lb}}$ represents the lower disincentive parameter, $\gamma_{\mathrm{ub}}$ represents the upper disincentive parameter, and $\kappa_{1}$ represents the incentive CAR, which satisfy: $0<\lambda_{\mathrm{lb}}<\lambda_{\mathrm{ub}}$, and $\gamma_{\mathrm{lb}}, \gamma_{\mathrm{ub}}, \kappa_{1} \in(0,1)$.

Let us add the LDR-RR into the model of Iori et al. by incorporating it into the following calculation of RR $R_{k, t}$ :

$$
R_{k, t}=R_{k, t}^{p}+R_{k, t}^{s}+R_{k, t}^{\mathrm{LDR}}=\rho_{p} D_{k, t}+\rho_{s} D_{k, t}+R_{k, t}^{\mathrm{LDR}}=\rho D_{k, t}+R_{k, t}^{\mathrm{LDR}},
$$

where $R_{k, t}^{p}$ is the primary RR and $R_{k, t}^{s}$ is the secondary RR, where $\rho_{p}, \rho_{s} \in(0,1)$. Here, we use the RR portion $\rho=\rho_{p}+\rho_{s}$. In [Bank of Indonesia Regulation, 2010], the values of $\rho_{p}, \rho_{s}, \lambda_{\mathrm{lb}}, \gamma_{\mathrm{lb}}, \lambda_{\mathrm{ub}}, \gamma_{\mathrm{ub}}$, and $\kappa_{1}$ are given $8 \%, 4 \%, 78 \%, 100 \%, 0,1,0,2$, and $14 \%$, respectively. 
The simulation in Figure 1 and Figure 2 (except for $\rho$ ) are clear in terms of observations and interpretations even though they only use four different values. A similar technique cannot be applied to the LDR-RR parameters because it cannot be concluded from the simulation results what happened to the $\rho$ parameter. Therefore, the simulation for the LDR-RR parameters uses a similar method as in Figure 3, which uses the number of surviving banks at the end of simulation $S_{T}$ as the measure of banking stability, and using the polynomial fitting polyfit in Matlab software to fit the result.

The lower limit of LDR target on the LDR-RR instrument serves as the minimum LDR limit for banks to avoid excess liquidity, as happened in Indonesia in the period 2005-2008 [Gunadi, Harun, 2011]. The effect of this parameter on the banking stability is shown in Figure 4, $a$. The value of $S_{T}$ is approximated by a polynomial of degree three given by the following equation:

$$
S_{T}\left(\lambda_{\mathrm{lb}}\right)=-136,18 \lambda_{\mathrm{lb}}^{3}+173,17 \lambda_{\mathrm{lb}}^{2}-43,27 \lambda_{\mathrm{lb}}+253,3 .
$$

The maximum value of $S_{T}\left(\lambda_{\mathrm{lb}}\right)$ is reached when $\lambda_{\mathrm{lb}}=69,55 \%$.

The upper limit of LDR target acts as the maximum limit for the bank's LDR to control credit growth so that it is not excessive. Banks that disburse too much credit without being supported by sufficient capital are concerned that they will not be able to absorb credit risk properly. Therefore, an upper limit for LDR is needed. However, if the bank's capital is sufficient for the incentive CAR, then this upper limit can be ignored. The effect of this parameter on the banking stability is presented in Figure $4, b$. The value of $S_{T}$ obtained is approximated by the quadratic function given by

$$
S_{T}\left(\lambda_{\mathrm{ub}}\right)=-30,81 \lambda_{\mathrm{ub}}^{2}+88,97 \lambda_{\mathrm{ub}}+203,05,
$$

where the maximum value of $S_{T}\left(\lambda_{\mathrm{ub}}\right)$ coincides with $\lambda_{\mathrm{ub}}=144,39 \%$.

The impact of the lower disincentive parameter on the banking stability is presented in Figure 4, c. It can be seen that, the larger the lower disincentive parameter, the more stable the banking system. This means that a sufficiently large lower disincentive parameter will further stabilize banks with the given parameter values. Unlike the case considered above, this time linear regression was carried out to approach $S_{T}$, which resulted in the following equation:

$$
S_{T}\left(\gamma_{\mathrm{lb}}\right)=251,41+81,25 \gamma_{\mathrm{lb}}
$$

The effect of the upper disincentive parameter on the banking stability is shown in Figure 4, $d$. The value of $S_{T}$ is approximated by the following three-degree polynomial:

$$
S_{T}\left(\gamma_{\mathrm{ub}}\right)=-133,61 \gamma_{\mathrm{ub}}^{3}+270,82 \gamma_{\mathrm{ub}}^{2}-150,37 \gamma_{\mathrm{ub}}+281,88 .
$$

The maximum value of $S_{T}\left(\gamma_{\mathrm{ub}}\right)$ in Figure $4, d$ is satisfied by $\gamma_{\mathrm{ub}}=0$. This means that the absence of disincentives when the bank's LDR exceeds the upper target limit will make the banking system more stable in this model.

The incentive CAR is intended as a benchmark for the bank's CAR that has LDR above the upper limit of LDR target. A bank's CAR which is not less than the incentive CAR is designed to be able to reduce various kinds of risks well. Figure $4, e$ shows the effect of incentive CAR on the banking stability. The value of $S_{T}$ is approximated by the following three-degree polynomial:

$$
S_{T}\left(\kappa_{1}\right)=14598,97 \kappa_{1}^{3}-8670,08 \kappa_{1}^{2}+1432,71 \kappa_{1}+195,95,
$$

with the maximum value of $S_{T}\left(\kappa_{1}\right)$ reached when $\kappa_{1}=11,75 \%$. 


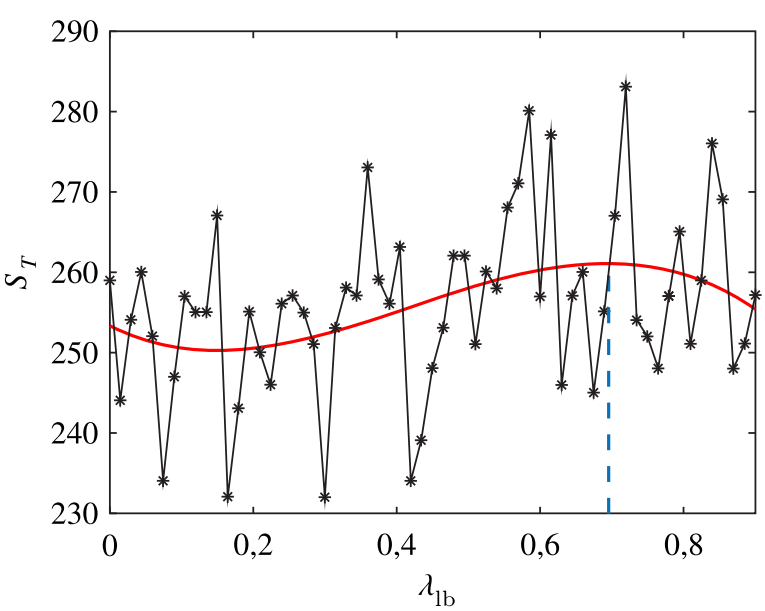

(a)

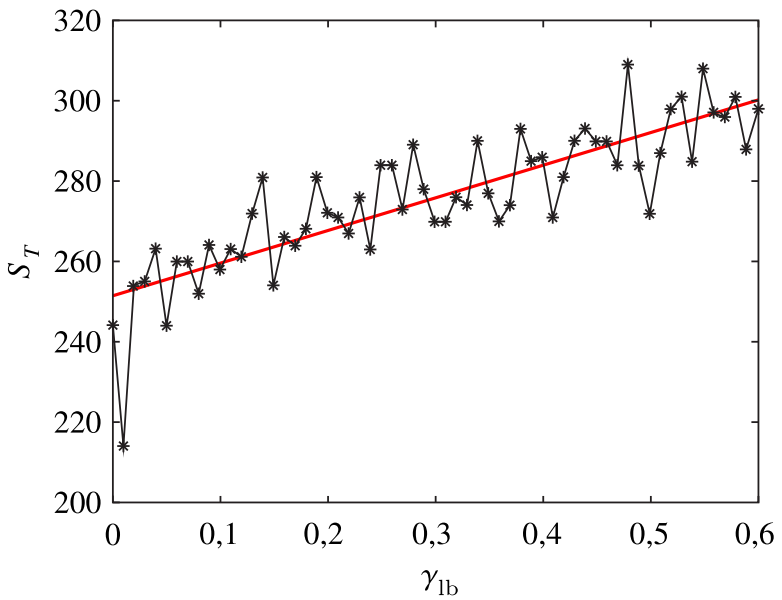

(c)

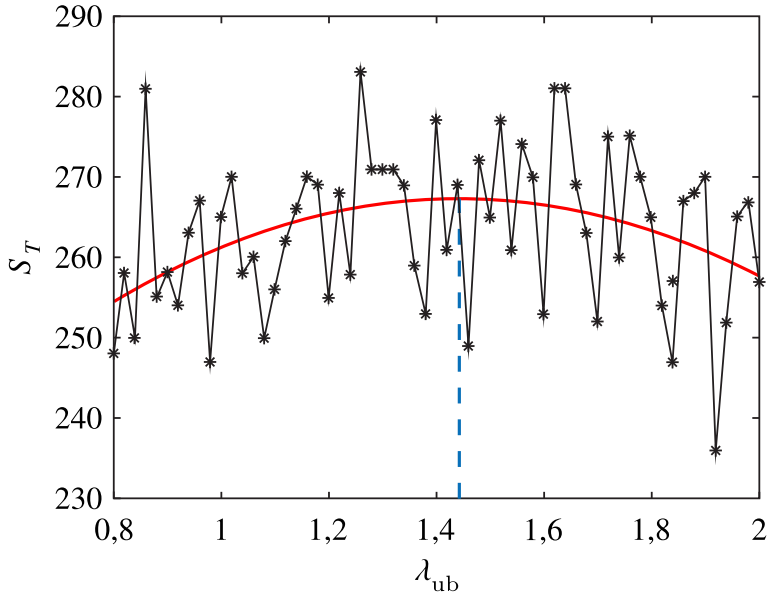

(b)

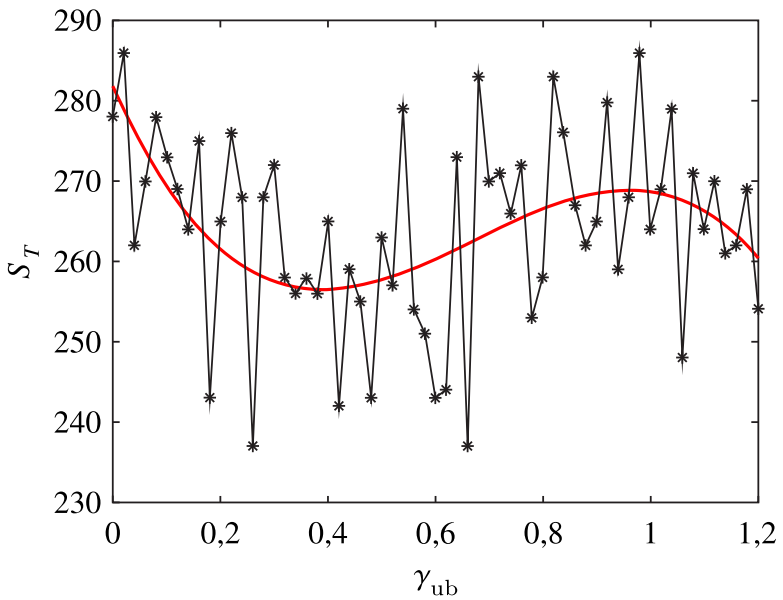

(d)

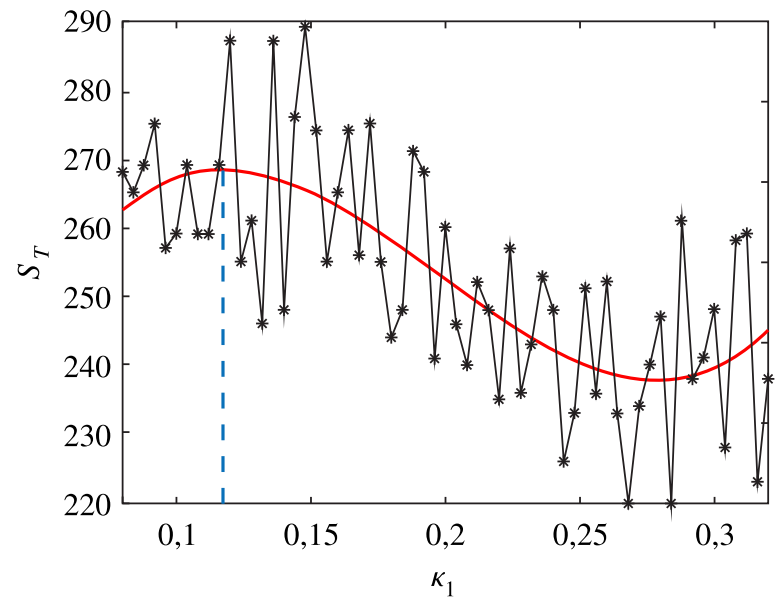

(e)

Figure 4. Relation between the number of surviving banks at the end of simulation $S_{T}$ with the LDR-RR parameters. The black dots represent values of $S_{T}$ with respect to these parameters that are obtained from the model simulation. The red line is a polynomial curve that gives the best fit. Panels (a), (b), (c), (d), and (e) show the lower limit of LDR target $\lambda_{\mathrm{lb}}$, the upper limit of LDR target $\lambda_{\mathrm{ub}}$, the lower disincentive parameter $\gamma_{\mathrm{lb}}$, the upper disincentive parameter $\gamma_{\mathrm{ub}}$, and the incentive CAR $\kappa_{1}$, respectively. The higher $S_{T}$, the more stable the banking system 


\section{Conclusion}

Banking system modeling is a multidisciplinary subject that connects mathematics, finance, and computer science. This paper provides sufficient resources for wider audiences (not only economists and bankers, but also mathematicians and computer scientists) to understand the abstract of the banking network system, particularly about the interbank borrowing-lending mechanism via mathematical and computational methods. Our full algorithm is straightforwardly applicable for possible future works. The simulation technique using the best polynomial fit for a number of surviving banks at the end of simulation can be used for analyzing a macroprudential policy instrument in Indonesia, called loan-todeposit ratio based reserve requirement. Based on this analysis, we can get the optimal value of the instrument's parameters for optimizing the banking stability. The model and the given technique can be developed to analyze other economics or banking aspects that emerge in the banking system. Further model developments can be done by adding various features in the real banking system [Pan, Fan, 2020; Jiang, Fan, 2021], using different types of networks [Pan, Fan, 2021], or combining with other banking network models [Georg, 2011]. The developments can also be carried out by using another approach for modeling bank balance sheet components [Ansori et al., 2021].

\section{References}

Allen F., Gale D. Financial contagion // Journal of Political Economy. - 2000. - Vol. 108. - P. 1-33. Ansori M.F., Sidarto K.A., Sumarti N., Gunadi I. Dynamics of Bank's Balance Sheet: A System of Deterministic and Stochastic Differential Equations Approach // International Journal of Mathematics and Computer Science. - 2021. - Vol. 16, no. 3. - P. 871-884.

Bank of Indonesia Regulation. PBI No.12/19/PBI/2010 tentang Giro wajib Minimum Bank Umum Pada Bank of Indonesia Dalam Rupiah Dan Valuta (in English: about Reserve Requirement of Commercial Bank to the Bank of Indonesia in Rupiah and Currency). - 2010.

Bargigli L., di Iasio G., Infante L., Lillo F., Pierobon F. The multiplex structure of interbank networks // Quantitative Finance. - 2015. - Vol. 15, no. 4. - P. 673-691.

Battiston S., Delle Gatti D., Gallegati M., Greenwald B., Stiglitz J. E. Liaisons dangereuses: Increasing connectivity, risk sharing, and systemic risk // Journal of Economic Dynamics and Control. 2012. - Vol. 36, no. 8. - P. 1121-1141.

Brummitt C.D., Kobayashi T. Cascades in multiplex financial networks with debts of different seniority // Phys. Rev. E. - 2015. - Vol. 91, no. 6. - P. 062813.

Caccioli F., Barucca P., Kobayashi T. Network models of financial systemic risk: a review // Journal of Computational Social Science. - 2018. - Vol. 1. - P. 81-114.

Eboli M. An Algorithm of Propagation in Weighted Directed Graphs with Applications to Economics and Finance // International Journal of Intelligent Systems. - 2010. - Vol. 25. - P. 237-252.

Elsinger H. Financial Networks, Cross Holdings, and Limited Liability // Oesterreichische Nationalbank Austria. - 2009. - P. 1-31.

Eisenberg L., Noe T. H. Systemic Risk in Financial Systems // Management Science. - 2001. - Vol. 47, no. 2. - P. 236-249.

Fan H., Pan H. The Effect of Shadow Banking on the Systemic Risk in a Dynamic Complex Interbank Network System // Complexity. - 2020. - P. 1-10.

Gai P., Kapadia S. Contagion in financial networks // Proceedings of the Royal Society A: Mathematical, Physical and Engineering Sciences. - 2010. - Vol. 466, no. 2120. - P. 24012423.

Gao Q., Fan H. Effect of the Dynamic Macroeconomic Fluctuation on the Stability of a Banking Network System with Scale-Free Structure // Mathematical Problems in Engineering. - 2020. P. $1-11$. 
Georg C.-P. The effect of the interbank network structure on contagion and common shocks // Deutsche Bundesbank Discussion Paper. - 2011. - No. 12.

Georg C.-P., Poschmann P. Systemic risk in a network model of interbank markets with central bank activity // Jena Economic Research Papers. - 2010. - No. 33. - P. 1-33.

Gunadi I., Harun C.A. Revitalising reserve requirement in banking model: An industrial organisation approach // SEACEN Occasional Papers. - 2011. - No. 51.

Hüser A.-C. Too Interconnected to Fail: A Survey of the Interbank Networks Literature // SAFE Working Paper. - 2015. - No. 91. - P. 1-42.

Iori G., Jafarey S., Padilla F. G. Systemic risk on the interbank market // Journal of Economic Behavior \& Organization. - 2006. - Vol. 61. - P. 525-542.

Jiang S., Fan H. Systemic Risk in the Interbank Market with Overlapping Portfolios // Complexity. 2019. - P. 1-12.

Jiang S., Fan H. Systemic risk in the interbank market with overlapping portfolios and cross-ownership of the subordinated debts // Physica A. - 2021. - Vol. 562. - P. 125355.

May R. M., Arinaminpathy N. Systemic risk: the dynamics of model banking systems // Journal of The Royal Society Interface. - 2010. - Vol. 7, no. 46. - P. 823-838.

Nier E., Yang J., Yorulmazer T., Alentorn A. Network models and financial stability // Bank of England Working Paper. - 2008. - No. 346. - P. 1-28.

Pan H., Fan H. Research on the Stability of the Banking System With Shadow Banking Under Macroeconomic Fluctuation // Frontiers in Physics. - 2020. - Vol. 8, no. 338. - P. 1-11.

Pan H., Fan H. The Stability of Banking System with Shadow Banking on Different Interbank Network Structures // Discrete Dynamics in Nature and Society. - 2021. - P. 1-15.

Poledna S., Molina-Borboa J.L., Martinez-Jaramillo S., van der Leij M., Thurner S. The multi-layer network nature of systemic risk and its implications for the costs of financial crises // Journal of Financial Stability. - 2015. - Vol. 20. - P. 70-81.

Rogers L.C.G., Veraart L.A.M. Failure and Rescue in an Interbank Network // Management Science. - 2013. - Vol. 59, no. 4. - P. 882-898.

Visentin G., Battiston S., D'Errico M. Rethinking Financial Contagion // SSRN Papers. - 2016.

Wijayanti R., Adhi N.M., Harun C.A. Effectiveness of macroprudential policies and their interaction with monetary policy in Indonesia // BIS Paper. - 2020. - No. 110. - P. 31-50. 